\title{
Francisco Suárez acerca do consentimento e da obrigação política ${ }^{1^{*}}$ Francisco Suárez on Consent and Political Obligation
}

\begin{abstract}
Resumo: Os intérpretes discordam quanto a origem que Francisco Suárez atribui a obrigação e a sujeição política. De acordo com alguns, Suárez, como outros contratualistas, acredita que é o consentimento dos indivíduos que causa a obrigação política; outros, porém, afirmam que para Suárez a obrigação política não deriva do consentimento dos indivíduos. Em respaldo a esta tese eles invocam a opinião de Suárez de que o poder político emana da cidade por meio de "decorrência natural." Eu argumento que a análise de obras menos estudada de Suárez, como o De voto e o De iuramento, mostra que, para Suárez, o consentimento causa tanto a obrigação política da cidade e quanto a dos cidadãos. Além do mais, uma inspeção mais acurada da noção de causalidade por decorrência natural dentro da metafísica suareziana mostra que o que emana do corpo político não é, como sustentado, a sujeição e a obrigação política, mas sim o direito à autonomia da cidade. E visto que para Suárez a obrigação política se origina no consentimento, então não é errado considerá-lo um contratualista.

Palavras-chave: Francisco Suárez, consentimento, obrigação política, decorrência natural, poder político.
\end{abstract}

\begin{abstract}
Interpreters disagree on the origin that Francisco Suárez assigns to political obligation and correlative political subjection. According to some, Suárez, as other social contract theorists, believes that it is the consent of the individuals that causes political obligation. Others, however, claim that for Suárez, political obligation is underived from the individuals' consent which creates the city. In support of this claim they invoke Suárez s view that political power emanates from the city by way of "natural resultancy". I argue that analysis of Suárezs less studied De voto and De iuramento reveals that, for Suárez, consent causes both the city and the citizens political obligation. Moreover, close inspection of the notion of causation by natural resultancy within Suárez s metaphysics shows that what emanates from the body politic in this fashion is not, as claimed, political subjection and political
\end{abstract}

\footnotetext{
${ }^{1}$ Tradução autorizada pela Koninklijke Brill NV do artigo de Daniel Schwartz, "Francisco Suárez on Consent and Political Obligation”, Vivarum 2008, vol. 46, pp. 59-81, Bruno D’ambros.

*Doutorando em Filosofia pela Universidade Federal do Paraná . Mestrado em Filosofia pela Universidade Federal de Pelotas . Bacharel em Ciências Sociais pela Universidade Federal de Santa Catarina. Membro dos grupos de pesquisa CNPQ "Razão prática e moral" (UFPEL) e "Ética, filosofia jurídica e política” (UEL). Membro do corpo editorial da Revista Seara Filosófica (UFPEL). Email: dambrosbruno@gmail.com
}

${ }^{* *}$ Texto original em inglês publicado em: SCHWARTZ, Daniel. Francisco Suárez on Consent and Political Obligation. Vivarium, Vol. 46, No. 1 (2008), pp. 59-81. 
obligation, but rather the city's right to self-mastership. Because for him political obligation does originate in consent it is not incorrect to regard Suárez as a social contract theorist.

Keywords: Francisco Suárez, consent, political obligation, natural resultancy, political power

Francisco Suárez atribui um papel central ao consentimento em sua explicação da origem do corpo político. ${ }^{2}$ Mas qual é o caminho causal exato que leva do consentimento individual a comunidade política até a emergência da obrigação política? Os intérpretes como Otto Gierke, Paulo Merêa, Ignácio Gómez Robledo, Paulo Alves Durau, Thomas Schröck e outros, argumentam que, para Suárez, o consentimento não causa diretamente a obrigação política. Nesta interpretação, assim como o direito de governar o próprio corpo "naturalmente decorre" de se ser uma pessoa e é independente dos meios pelos quais ele foi gerado, assim o direito da cidade de governar sobre os cidadãos naturalmente flui do fato de se ser uma cidade e é independente do modo no qual ele foi produzido (ou seja, pelo consenso). Gierke diz que Suárez (e Luis de Molina) "justificam um poder de controle sobre as partes pelo todo social que, uma vez que ele surgiu -apesar de sua origem contratual, não é menos independente das vontades dos indivíduos."3

Como Gierke e Schröck notam, isso significaria que Suárez não deveria ser classificado entre os contratualistas. ${ }^{4}$ É um princípio central dos contratualistas que os cidadãos contraem uma obrigação para uma autoridade política porque eles expressaram um consentimento tácito ou

2 Potestas in uno, et subjectio in alio sunt correlativa." Francisco Suárez, De legibus, ac Deo legislatore , III.33.4 (Doravante D.L, número do livro em numerais romanos, seguido pelo capítulo e seção em numerais arábicos). Todas as referências e citações em latim de Suárez são tomadas da Opera Omnia (Paris: Vivès, 1856-1868) 28 volumes, (doravante Opera). Traduções inglesas do D.L são tiradas de Selections from Three Works of Francisco Sudrez, 5, James Brown Scott ed. (Oxford, 1944) vol. 2. (com leves correções quando necessário.) Todas as outras traduções de outras obras sãos minhas [do autor].

3 Otto Gierke, Natural Law and the Theory of Society 1500-180o, Ernest Barker, translation and notes (Cambridge, 1958), 51.

4 Suárez como um contratualista (ou pelo menos como um precursor dos contratualistas) foi defendido, por exemplo, em: Patrick Riley, "Social Contract" in David Miller ed., The Blackwell Encyclopaedia of Political Thought (Oxford, 1987) 479, Quentin Skinner, The Foundations of Modern Political Thought, vol. 2 (Cambridge, 1988) 162, e Arthur P. Monahan, From Personal Duties towards Personal Rights: Late Medieval and Early Modern Political Thought, 1300-16oo (Montreal and Kingston, Ont., 1994) 182. Contrário à leitura contratualista, Gierke tem argumentado que Suárez é um organicista eclético (Natural Law, 45), e Schröck que ele é um "holista cristão aristotélico jusnaturalista.” Thomas Schröck, 'Anachronism All Around: Quentin Skinner on Francisco Suárez', Interpretation 25 (1997) 92. 
hipotético. ${ }^{5} \mathrm{Na}$ "interpretação tradicional" de Suárez citada acima - de modo algum compartilhada por todos os intérpretes - o consentimento não é um meio de contratar uma obrigação política; o consentimento é o meio de se criar um ser que naturalmente possui uma autoridade política sobre suas partes.

Mas eu argumento que essa interpretação de Suárez é baseada sobre uma compreensão errada dos textos De legibus e Defensio fides sobre a obrigação política, e Suárez pode ser mais acuradamente acessado se se dirige a atenção sobre suas obras não políticas menos estudadas, tais como De voto e De iuramento, que discutem o tópico mais geral das obrigações morais voluntariamente assumidas. Esta análise revela que, para Suárez, o consentimento produz obrigação tanto para a cidade quanto para os cidadãos. Como resultado, Suárez não deveria ser excluído do rol dos contratualistas nos fundamentos sugeridos por Gierke e por aqueles que compartilham sua interpretação.

A chave da interpretação tradicional é a visão de Suárez de que a sujeição política é causada pela cidade através de "decorrência natural" (uma forma de emanação), ao invés do consentimento dos indivíduos que constituem a cidade. Uma análise mais acurada deste modo causal dentro de seu habitat - a metafísica suareziana - revela, porém, que o efeito da "decorrência natural" da cidade não é, como a interpretação tradicional sustenta, a sujeição política dos cidadãos. Na verdade o efeito é o direito original e alienável da cidade em ser autônoma. Portanto é errôneo considerar o consentimento dos indivíduos e a cidade como causas a competir por um e mesmo efeito.

Este artigo apresenta quatro objeções diferentes à visão de que, para Suárez, é o consentimento que cria obrigação e autoridade política. As objeções são baseadas nas seguintes alegações: (i) o consentimento não tem nenhuma função justificativa no capítulo do De legibus no qual Suárez declara sua intenção em estabelecer a legitimação moral da potestas política; (ii) Suárez frequentemente argumenta que a potestas da cidade é independente das vontades que criam a cidade; ${ }^{6}$ (iii) Suárez notavelmente 
se abstêm de recorrer a transferir ou alienar dos direitos de auto-governo quando explica a origem do direito do soberano de governar; ${ }^{7}$ (iv) enquanto, para Suárez, o consentimento cria a comunidade política, o direito da comunidade de governar sobre seus membros é dito como emanado da verdadeira natureza da comunidade, ao invés de ser um efeito direto do consentimento dos indivíduos. ${ }^{8}$

As asserções (ii), (iii) e (iv) foram feitas pelos interpretes que defendem uma leitura não-contratualista de Suárez; e a asserção (i) não tem, aparentemente, plausibilidade suficiente para merecer uma consideração.

De início duas coisas são importantes notar. Primeiro, Suárez discute dois atos diferentes de consentimento: o consentimento individual para constituir uma comunidade política (consentimento constitutivo) e o consentimento da comunidade requerido por um pretenso governante para um mandato. ${ }^{9}$ A discrepância entre defensores e críticos de uma leitura contratualista de Suárez concerne ao papel causal do consentimento constitutivo na criação do poder político e isso não tem a ver com a natureza do que é consentido (o consentimento de se formar uma comunidade política.)

Segundo, há um grau de latitude que se liga às referências de Suárez sobre o consentimento constitutivo. Ele se refere amplamente a "consentimento," a um "ato especial de volição" pelo qual a comunidade é constituída, ${ }^{10}$ a um "pacto tácito ou expresso," ${ }^{11}$ e a "intervenção da

(originalmente na Revista da Universidade de Coimbra, vol. VI, 1917) ; Paulo Durau Alves, A filosofia política de Suárez (Porto, 1949), 29; Ignacio Gómez Robledo, El origen del poder político según Francisco Suárez (Mexico City, 1948), 108-109; Gierke, Natural Law., 51; Schröck, 'Anachronism', 110 7 Schröck, Anachronism', 103

8 Merêa, 'Escolástica e jusnaturalismo: O problema da origem do poder civil em Suárez e Pufendorf ' in Sobre o origem do poder civil (originally in Boletim da Facultade de Direito da Universidade de Coimbra , Coimbra, vol XIX, 1943), Gierke, Natural Law , 51, Schröck, Anachronism', 102-6, Durau Alves, A filosofia política de Suárez , 29, Gómez Robledo, El origen del poder político , 113-114, 127.

9 Estes dois tipos de consentimento são combinados na apresentação de Skinner sobre Suárez, em seu Foundations, II, 162

10 D.L. III.2.4 menciona "volição especial, ou ato comum de consentimento."

11 Como em De opere sex dierum (doravante O.S.D.) V.7.3. (in Opera, voi. 3). 
vontade humana" que atualiza a comunidade. ${ }^{12}$ Suárez parece usar estes termos para se referir a uma única e mesma coisa. Portanto, todas estas frases são tomadas aqui como informativas sobre sua visão sobre o consentimento.

\section{O consentimento e a naturalidade da obrigação política}

Nesta seção eu discuto o intrigante fato de o consentimento não ter qualquer papel importante na demonstração central da justificação moral da sujeição política no capítulo de abertura do terceiro livro do De legibus de Suárez. Tal omissão pode ser vista como confirmação de que é o consentimento que cria a obrigação política em Suárez. Mas eu argumento que, se reconsiderarmos o propósito de Suárez neste capítulo, então veremos que esta não é uma afirmação possível.

Ao introduzir o que chama de um esforço para dar clareza moral para a potestas política, Suárez começa perguntando se "é possível [...] aos homens comandarem outros homens sujeitando-os pelas próprias leis humanas?" ${ }^{13}$ A pertinência desta questão é sua crença de que "o homem é por sua natureza livre e sujeito a ninguém, exceto ao criador.” Tal crença levanta a preocupação de que a potestas possa ser "contrária a ordem natural" e talvez, por isso, envolva tirania. ${ }^{14}$ Ao dizer que "o homem é livre por natureza” Suárez poderia reformular sua visão sobre o direito natural à liberdade. Este direito pode ser renunciado, por exemplo, ao se vender sua liberdade. ${ }^{15}$

Suárez aborda o problema distinguindo entre um estado prépolítico e político. No estado pré-político, o homem, que é um "animal social”, naturalmente se associa em comunidades domésticas ou famílias. As famílias não são auto-suficientes; elas não tem nem os ofícios, nem as

12 D.L. III. 1.11., o consentimento é referido como idêntico a intervençaõ das vontades humanas envolvidas em fazer pactos, concordâncias e obrigações em D.L. II. 1 4.7, II.1 4.1 1. Ver também O.S.D. V.7.7

13 D.L. III.1.1.

14 Para uma discussão paralela ver Defensio fidei catholicae, et apostolicae adversus anglicanae sectae errores (in Opera, vol. 24, doravante D.F) III. 1.2, onde Suárez sustenta sua preocupação em termos parecidos (com a preocupação adicional de que a sujeição política pode diminuir a dignidade devida aos seres humanos em virtude de serem criado à imagem divina.

15 "Pela razão de que o homem é senhor de sua própria liberdade, é possível para ele vender ou alienar sua própria liberdade.” D.L. II. 14. 18. 
artes, nem o conhecimento de todas as coisas necessárias para a vida humana.

Suárez acrescenta que, se as famílias fossem divididas umas das outras, a paz não poderia ser preservada entre os homens, e os erros não poderiam ser propriamente prevenidos ou desforrados. ${ }^{16}$ Aqui Suárez pode estar sustentando a idéia de que, arriscando um anacronismo, um estado de guerra precede e justifica a constituição de um soberano. A intimidação de um estado de guerra (e de injustiça) é surpreendente, dado que ele mais tarde afirma que sua teoria se aplica a um estado de inocência hipoteticamente estendido. ${ }^{17}$ Isto é, de acordo com Suárez, mesmo se o pecado original não tivesse sido cometido, ainda assim seria o caso que as famílias teriam razões suficientes (incluindo o "estado de guerra razões") para estabelecer algum tipo de comunidade política.

Suárez argumenta que os habitantes do estado pré-político são capazes de conceber um possível, mas ainda não atual, estado político, onde há cooperação entre as famílias para algum propósito. Estes habitantes também seriam capazes de perceber que, como em qualquer "comunidade doméstica ou família, há por sua própria natureza, uma potestas adequada para o governo desta comunidade, que reside principalmente no chefe da família," assim é com a comunidade política porque "nenhum corpo pode ser preservado ao menos que exista algum princípio cuja função é prover e procurar seu bem comum." ${ }^{\text {} 8}$

Disso Suárez conclui que apesar de ser verdade que o homem nasceu com um direito natural à liberdade, ele nasceu também com a capacidade de pôr a si mesmo sob o dever de obedecer outros seres humanos (presumivelmente por ter a capacidade de estabelecer comunidades). ${ }^{19}$ Portanto, uma situação na qual os indivíduos se colocam

16 D.L. III. 1.4

17 D.L. III. 1.12

18 D.L. III. 1.4-5 citando Tomás de Aquino, De regimine principium , I, $i$.

19 Por sujeição Suárez quer dizer toda sujeição legitimada, que é o direito de alguém a liderar e, correlativamente, o dever de alguém a obedecê-lo. Note que a questão que incita a discussão de Suárez é se alguns indivíduos podem comandar outros através da lei em modos que vinculam-nos a obedecer (per proprias leges eos obligando), ao invés de se alguns indivíduos tem a capacidade de fazer outros se comportar do modo que eles desejam que se comportem. 
sob este dever não é contra as injunções da lei natural, mesmo se tal dever não pertence a alocação original dos direitos e obrigações. ${ }^{20}$

A tentativa central de Suárez em mostrar a permissibilidade moral do governo político foca sobre a demonstração de sua necessidade e conveniência. Isso não concede um papel saliente ao consentimento, que é confuso, pois se há um único lugar onde o consentimento deveria ser abordado é precisamente aqui. O mesmo enigma se apresenta na explicação paralela de Suárez sobre a origem do governo político em Defensio fidei. ${ }^{21}$

Em ambas as instâncias, nós esperamos Suárez dizer, em consonância com Locke: "os homens sendo, como tem sido dito, por natureza, todos livres, iguais e independentes, ninguém pode ser tirado de seu estado, e sujeitado ao poder político de outro, sem seu próprio consentimento." ${ }^{22}$ Mas ao invés de resolver o problema assim, Suárez somente demonstra a conveniência em se formar um estado político. Mas mostrar a conveniência de algo é diferente de mostrar que ele não violenta nossos direitos naturais. O fato do consentimento ter um papel tão marginal no capítulo no qual ele seria mais necessário, parecere pôr Suárez longe dos contratualistas.

Ainda, uma correta avaliação da tarefa escolhida de Suárez neste capítulo nos permite excluir esta conclusão. Afinal, qual é o propósito de Suárez neste capítulo de abertura? Alguém replicará que sua intenção é mostrar que a sujeição política não viola a liberdade original de alguém. Sob esta luz, o capítulo exige o uso do argumento do consentimento; ele nos desafia quando atribui ao consentimento um papel meramente marginal. Entretanto eu creio que Suárez está preocupado com uma tarefa diferente: mostrar que a sujeição política não é menos natural que a nãosujeição política. Isso ele faz quando argumenta que nós somos naturalmente inclinados a uma comunidade política e que tal comunidade

\footnotetext{
20 Veja D.L. III. 1.11: "Embora o homem não foi criado ou nasceu sujeito a potestas de um príncipe, ele nasceu capaz de sujeição a tal potestas. Portanto, a sujeição não está, mesmo se ela não flui imediatamente da natureza, em oposição à lei natural prescritiva. Ao contrário, é consonante com a razão natural que a counidade humana deveria estar sujeita a alguém, mesmo que a lei natural não tem de si mesma e sem intervenção da vontade humana, criado a sujeição política." Como será discutido mais tarde, para Suárez a razão natural é, no sentido aqui aludido, lei natural.
}

21 D.F. 111.15. O título da seção é "Utrum principatus politicus legitimus et a deo sit."

22 John Locke, Two Treatises of Government, Peter Laslett, ed. (Mentor: New York, 1965) II.8.95, p. 
não pode funcionar sem um governo. Nós, portanto, temos uma inclinação natural a nos pôr sob a obrigação política.

Nossa liberdade original se apresenta aqui como uma razão para inspecionar a "naturalidade" da sujeição política. Não é a perda da liberdade original que preocupa Suárez, mas sim se a tendência a perdê-la é natural. Já que essa é a principal preocupação do capítulo sob exame, não é necessário tratar do consentimento.

\section{II. $O$ consentimento e a geração da cidade}

O consentimento entra na discussão de Suárez quando ele começa a determinar, no capítulo dois, quem tem o direito de fazer leis. Aqui o consentimento tem dois papéis relacionados: ele nos permite distinguir as unidades sociais que tem o direito de legislar sobre elas mesmas das unidades sociais que não tem este direito, e nos permite individualizar as unidades sociais dentro da primeira categoria.

Suárez distingue entre uma mera agregação de indivíduos e um corpo político próprio que ele chama de "união moral"

A multidão de homens deveria ser vista - [...] com respeito a volição especial, ou consentimento comum pelo qual eles são congregados juntos em um corpo político - através de um vínculo de companheirismo e para o propósito de ajudar um ao outro no alcance de um único fim político. Assim visto, eles formam um único corpo místico ${ }^{23}$ que, moralmente falando, pode ser considerado como unidade essencial (moraliter potest dici per se unum. $)^{24}$

\footnotetext{
23 No tempo de Suárez, o termo sacramental "corpo místico" era largamente usado em referência às associações humanas. Sobre as transformações do sentido desta noção, ver Ernst Kantorowicz, The Kings Two Bodies: A Study in Mediaeval Theology (Princeton, NJ, 1957), 193-232. Também em Francis Oakley, 'Figgis, Constance, and the Divines of Paris', American Historical Review, 75 (1969), 369-386; 'Natural Law, The Corpus Mysticum, and Consent in Conciliar Thought from John of Paris to Mathias Ugonius', Speculum , 56 (1981), 786-810; '"Anxieties of Influence": Skinner, Figgis, Conciliarism and Early Modern Constitutionalism', Past and Present, 151 (1996), 105 and Brian Tierney, Foundations of the Conciliar Theory: The Contribution of the Medieval Canonists from Gratian to the Great Schism (Cambridge, 1955)

24 D.L. III. 2.4, precedido por: "advertendum est, multitudinem hominum duobus modis consid- eran; primům solum ut est aggregatum quoddam sine ilio ordine, vel unione physica, vel mora quomodo non efficiunt unum quid nec physice, nec moraliter: et ideo non sunt proprie unum corpus politicum, ac proinde non indigent uno capite, aut principe."
} 
Apesar dos indivíduos terem razões para formar um corpo político, eles não constituem um corpo político até que eles decidam aprovar estas razões e agir sobre elas. Que tipo de ato é necessário para gerar a cidade? Para Suárez, este ato não pode simplesmente ser a decisão das famílias em viver em proximidade e interação pacífica. Tal proximidade cria, no máximo, uma certa familiaridade ou mesmo amizade, mas falha em produzir uma união moral (que, para Suárez, é sinônimo de comunidade). ${ }^{25} \mathrm{Na}$ verdade a união moral origina a assunção dos direitos e obrigações que fazem a vida política possível. Isso é feito através de um "pacto expresso ou tácito" entre os pretensos cidadãos para ajudarem uns aos outros, com seus consentimentos para subordinarem a si mesmos a um superior. ${ }^{26}$ Sem este pacto, o conglomerado social não pode se tornar uma "unidade moral." ${ }^{27}$

Para Suárez, há dois tipos de entidades morais. Entidades morais denominativas emergem de ações voluntárias. Elas diferem somente em razão da origem de entidades meramente físicas. Portanto, uma entidade moral denominativa não é em si mesma separada de uma entidade física. Uma casa é tanto uma entidade física e, se construída por construtores livres, também, denominativamente, uma entidade moral. Substancialmente ou "entitativamente" as entidades morais, por outro lado, podem ocorrer em conjunção com entidades físicas, mas são distintas delas e tem entes verdadeiros separados. Suárez exemplifica com obrigações oriundas de promessas, propriedades transferidas por vontade do proprietário, vínculo matrimonial, e o preço dos bens como determinados por lei. ${ }^{28}$

25 "A proximidade geográfica é insuficiente para criar uma comunidade. Dela só pode emergir uma certa vizinhança, a qual pode, no máximo, induzir a um tipo de amizade ou familiaridade, mas não uma unidade moral ou comunidade." O.S.D. V.7.3

26 Suárez expressa isso mais diretamente em O.S.D. V.7.3: uma comunidade requer "alguma união política, que não pode existir sem um pacto expresso ou tácito para ajudar cada um, não sem subordinação a algum superior, ou a um líder da comunidade, sem o que tal comunidade não pode existir."

27 A frase ocorre também em D.F.1.6.18: "Tu podes verdadeiramente chamar de comunidade política, ou mística, em virtude da conjunção especial em uma congregação que é moralmente unida [...]." Associações como universidades e colégios se aproximam mais de sociedades perfeitas quanto mais elas tem "perfectum regimen et moralem unionem". Ver O.S.D. V.7.3

28 De bonitate et malitia humanorum actuum, d. 1.3 em Opera, vol. 4 . 
Parece bem claro para Suárez que a comunidade política é uma entidade moral, ao menos denominativamente, que emerge da vontade do chefe das famílias. ${ }^{29}$ Porém, ao dizer que o corpo político pode, "moralmente falando," ser chamado de uma unidade per se, Suárez sugere que o estado não é só denominativamente moral. Ele é moral em si mesmo, não somente por razão de origem, assim como são as várias estruturas de direitos e obrigações (promessas, casamento, contratos, propriedade). Nesta visão, o consentimento que constitui a civitas de Suárez, causa a unidade pondo os anuentes sob uma estrutura de direitos e obrigações que vinculam uns aos outros. Um auxílio a esta interpretação é sua visão de que seria mais conveniente aos estudiosos filiarem-se aos jesuítas por votos solenes que geram obrigações, de modo a estarem "substancialmente unidos por uma verdadeira união moral."3o

Entre os direitos e obrigações que se destacam e que geram unidade moral, está a obrigação dos cidadãos em se subordinar a um superior comum, e o respectivo direito deste superior sobre eles. A obrigação do cidadão é "obedecer [ao líder] como a atos honestos que resultam em seu bem privado ou comum." ${ }^{31}$ É a sujeição que produz a unidade da cidade porque

esta unidade surge, em larga medida, da sujeição a um único e igual líder e a potestas de um superior comum, enquanto ademais, se não há algum governo, esse corpo não poderia ser direcionado a um fim comum e a um bem estar geral..$^{22}$

Portanto nós podemos seguramente dizer que, para Suárez, o consentimento é a causa de direitos e obrigações compartilhados, que os fazem em uma unidade moral ou uma cidade. Ademais, para ele, a unidade da cidade depende do consentimento dos cidadãos em subordinarem-se a algum superior. A obrigação e o direito político correlato não fluem da

29 Wilenius Reijo diz que "pode ser dito que a essência da sociedade são as normas legais que regulam sua vida.” Wilenius Reijo, The Social and Political Thought of Francisco Suárez, Acta Philosophica Fennica XV (Helsinski, 1963), 36.

30 De admissione scholarium, in De religione Societatis Jesu in particulars III. 1.4 em Opera, vol. $16 B$ 31 O.S.D. V.7.1

32 D.L. III.2.4. 
cidade como conseqüências, mas, sim, como necessários para sua existência.

\section{A independência da obrigação política das vontades}

O objetivo das seguintes três seções é refutar as três interpretações sobre a conexão entre o consentimento e a obrigação política em Suárez, associadas com o que eu tenho chamado de "interpretação tradicional” exposta por Gierke, Merêa, Gómez Robledo, Durau Alves e Schröck. Esta interpretação sustenta que, para Suárez, a obrigação e o direito político da cidade não deriva do ato de consentimento que cria a cidade, mas, sim, da própria cidade. Em analogia proposta por Durau Alvez e Gómez Robledo, assim como não se pode desenhar um triângulo e evitar que a soma de seus ângulos seja $180^{\circ}$ (propriedade necessária do triângulo), assim não se pode criar uma cidade sem criar um poder político. ${ }^{33} \mathrm{Na}$ interpretação de Merêas, o "poder pressupõe como condição o concurso das vontades humanas, mas sua origem está em Deus, que, providencialmente, em favor do gênero humano, fez a possessão do governo necessário e inerente à verdadeira natureza da sociedade." ${ }^{34}$ Schröck propõe uma interpretação similar. ${ }^{35}$ Entendido deste modo (incorretamente, em minha opinião), o pensamento de Suárez põe Gierke como paradoxical. Citando De legibus III, 3.6, Gierke escreve: "havia, na verdade, alguns jusnaturalistas que tentaram, a despeito de suas premissas individualistas, atingir a idéia de um universal que existia em seu próprio direito, e crer em um todo que dependesse de si mesmo. Os escritores eclesiásticos sobre filosofia jurídica, em particular, procuravam provar que a comunidade do povo, porém, era livremente criada por indivíduos e não derivava seus direitos deles; mas defendendo esse paradoxo, mesmo a habilidade de um Suárez só podia produzir um jeu d'esprit." ${ }^{6} 6$

33 Paulo Durau Alves, A filosofia política de Suárez, 29, Gómez Robledo, El origen del poder político, 120

34 Paulo Merêa, 'Suárez, Jurista , 40.

35 Schröck, 'Anachronism', 110

36 Gierke, Natural Latu , 51 
Uma das bases a afirmação de que a obrigação política não deriva do consentimento é a asserção de Suárez de que "quando a vontade dos indivíduos se reúne numa comunidade política, não está em poder de um indivíduo [non sit in hominum potestate] impedir esta jurisdição"37 e que em uma comunidade adequadamente constituída "esta potestas existe pela própria natureza das coisas, de modo que não está em poder dos homens congregar ou impedir tal potestas." ${ }^{8}$ Gierke conclui disso que, para Suárez, a cidade tem "um poder de controle sobre suas partes que, não obstante sua origem contratual, não é menos independente das vontades dos indivíduos." 39

Eu creio que essa interpretação comum de Suárez é errônea. A crença de Suárez na incapacidade da vontade humana em impedir a potestas política quando a cidade já está formada não habilita à conclusão de Gierke. Isso se torna claro quando se examina as posições de Suárez sobre a inevitabilidade dos direitos e das respectivas obrigações políticas dentro do contexto de suas discussões sobre a obrigação moral. Há uma semelhança quase literal entre as expressões usadas por Suárez em sua discussão sobre a obrigação política a aquelas que ele usa em seu tratamento de juramentos promissórios (iuramenta promissoria). Suárez repetidamente diz que, enquanto alguém tem poder em jurar ou não, alguém não tem poder de impedir as obrigações vinculantes que são os "efeitos naturais" daquele juramento, que é independente da vontade de alguém. Um exame superficial da seguinte passagem, e daquelas semelhantes a ela, ${ }^{40}$ suporta esta leitura:

37 D.L. III.3.2: "supposita volúntate hominum conveniendi in una politica communitate, non est in potestate eorum impedire hanc iurisdictionem: ergo signum est proxime non provenire ex eorum voluntatibus quasi ex propria causa efficienti."

38 "[E]st haec potestas ex natura rei, ita ut non sit in hominum potestate ita congregari et impe- dire hanc potestatem." D.L. III.2.4.

39 Gierke, Natural Law, 51. Ver também n.5.

40 Considere, por exemplo, a seguinte passagem adicional: "um juramento [...] fora de sua verdadeira natureza, produz uma obrigação independentemente da vontade de quem faz o juramento.” De juramento, II .7.4 em Opera, vol. 14: "enquanto tem a ver com a vontade da pessoa fazer um voto para prometer dada coisa, uma vez que a promessa tem sido feita ele não tem mais poder sobre tal obrigação, nem é a obrigação, propriamente falando, nascida de sua vontade, mas sim daquela lei natural ou divina que diz 'dê ao Senhor o que tens prometido.' De voto , IV.4.3 in Opera, vol. 14. Também em De juramento , II.7.16, Suárez escreve que a obrigação naturalmente segue-se do juramento. Ele argumenta que o fato de que os efeitos legais de se jurar não podem ser impedidos por nós mostra que que "essa obrigação não depende diretamente e contiguamente da vontade de alguém, 
Enquanto é da vontade livre do homem fazer ou não um juramento, não está em seu poder não se comprometer pelo juramento feito. A conseqüência é evidente, já que ele aplica a causa e não pode impedir o efeito. Se ele deseja aplicar a causa (e assim decorre o efeito) necessariamente deseja o efeito - mesmo se ele não deseja; assim como a pessoa que deseja pôr fogo em uma casa, supre a causa voluntariamente, mas o efeito segue necessariamente independente de sua vontade. ${ }^{41}$

Esta passagem faz claro que a independência da obrigação (moral ou política) da vontade de uma pessoa se relaciona somente com a incapacidade de subseqüentes atitudes volitivas para cancelar a obrigação, uma vez que ela tem sido voluntariamente criada. "Independência" neste contexto não significa que a obrigação não foi causada por um ato da vontade. Quando Suárez diz que a potestas é um "efeito natural” ou uma "conseqüência natural" da formação da comunidade social, ele pode estar descrevendo os efeitos morais do ato do consentimento dado. Como ele diz, uma obrigação que emerge de uma promessa "não depende diretamente e contiguamente de vontade de alguém, mas sim remotamente, tendo suas raízes no ato, do qual ela necessariamente flui, e não pode ser impedida. ${ }^{42}$ É neste sentido que Suárez assere os juramentos e promessas geradas como uma questão de efeito natural, vinculando obrigações, independente de se estas obrigações são desejadas durante ou depois da performance do ato. ${ }^{43}$

\section{Direito político sem alienação de direitos}

mas sim remotamente, tendo suas raízes no ato, do qual ele necessariamente flui, e não pode ser impedido.” Ver também De voto, 1.3.5

41 "Quia licet in volúntate hominis sit jurare vel non jurare, non est tarnen in potestate homi- nis ex juramento praestito non obligari; consequentia est evidens, quia qui potest adhibere causam et non potest effectum ejus impedire, si vult applicare causam, et eius effectum applicai, necessario vult effectum, etiamsi maxime nolit; ut qui vult applicare ignem domui, voluntarie quidem ponit causam, sed effectus necessario sequitur independen ter a volúntate ejus." De juramento, II.7.12

42 De voto, 1.3.5.

43 Em suporte a esta leitura, pode-se consultar também D.L. III.33.4, onde Suárez sugere que o ato voluntário de entrar uma jurisdição (se feito em completa consciência) é idêntido ao ato performativo de querer ser obrigado pelas leis vinculantes sobre tal jurisdição. Como uma conseqüência deste ato de consentimento, nós incorremos em obrigação política, mesmo se essa consenquencia moral do ato é em si mesma indesejada. 
Alguns intérpretes crêem que se o direito político não é resultado de uma transferência de direitos então ele não pode ser derivado do consentimento humano. Schröck, por exemplo, crê que a ausência de uma transferência de direitos prova que, para Suárez, o consentimento não legitima a comunidade política. ${ }^{44}$ Ele argumenta que "dado que o direito político não existe em cada indivíduo, e que as pessoas são incapazes de dar o que elas não possuem" 45 como pode o consentimento dos indivíduos, entendido como uma transferência putativa de direito, ser bem sucedido em legitimar uma comunidade política? Isso o leva a perguntar se não pode haver uma "qualidade holística para a doutrina do consentimento de Suárez, uma qualidade que antecipa a necessidade por transferência individual do direito político pelo consentimento.” ${ }^{46}$

Este holismo parece precipitado. A transferência de direito como um dispositivo que cria o direito em alguém não é absolutamente desconhecida para Suárez. Ele recorre a transferência de direitos autônomos (concebidos como a dívida de dominium sobre a liberdade de alguém $)^{47}$ para assim explicar a escravidão voluntária de si mesmo, bem como a maneira pela qual a comunidade pode perder a propriedade de um poder político para um líder estrangeiro em uma guerra justa. Entretanto a transferência de direitos não é o único meio de voluntariamente incorrer em obrigações. Considere os juramentos, votos e promessas. Se eu prometo ajudar minha mãe em sua velhice, ela tem direito a esta ajuda. Mas ela não é eo ipso a possuidora de um direito sobre parte do meu tempo livre durante sua velhice: ela não pode, por exemplo, determinar que eu usarei este tempo para auxiliar uma caridade que ela gosta, e ela nem pode transferir seu direito sobre parte do meu tempo livre para uma outra pessoa por doação ou venda. Direitos que surgem de promessas são às vezes transferíveis, mas isso é diferente de dizer que os direitos podem somente ser criados por uma transferência.

44 Schröck ('Anachronism', 103) cita D.L. III.2.1 como o lugar onde Suárez rejeita a transferência de direitos como a base do governo político, mas neste lugar Suárez está somente rejeitando que o governo político pode ser surgido da transferência de um direito para o governar sobre outros, como oposto ao direito de autonomia.

45 Citando D.L. 111.2.

46 Schröck, Anachronism', 103

47 D.L. III.3.7 
Suárez afirma repetidamente e de forma notável que as obrigações assumidas voluntariamente não precisam nem se originam em uma transferência de direito. Ele faz isso em sua discussão sobre os votos dos membros da Companhia de Jesus (castidade, pobreza e obediência), onde ele se pergunta se esses votos pressupõem ou efetuam por si mesmos uma traditio ou donatio sobe o corpo de alguém, sobre a posse de alguém ou sobre a vontade de alguém. Ele constantemente nega que as obrigações morais geradas pelos votos - entendidos por ele como promessas feitas a Deus - podem ser identificadas ou reduzidas àquelas originárias de uma transferência de direitos de alguém sobre uma coisa. ${ }^{48}$

Temos visto que a escolha de Suárez das frases para descrever os efeitos morais do consentimento constitutivo parecem quase literalmente sua descrição dos efeitos morais das promessas. Se, então, o consentimento à comunidade política é entendido como uma espécie de promessa de obedecer às regras políticas de uma comunidade, podemos falar de obrigação política sem necessidade de pressupor uma transferência de direitos.

Não só a criação do direito político não requer uma transferência de direitos, mas, para Suárez, uma transferência de direitos não é um meio desejável para criar tal direito. Suárez acredita que o direito político dos governantes sobre uma pessoa é diferente do direito de propriedade parcial ou total sobre a pessoa. ${ }^{49}$ Ao contrário de Hobbes, para quem o cidadão diz "desisto do direito de me governar", ${ }^{\circ}$ para Suárez, como visto, o consentimento dos cidadãos "em obedecer [o governante] em relação a ações honestas que redundam em seu bem privado ou no bem comum." ${ }^{11}$ Aqui os direitos dos governantes hobbesianos e suarezianos se diferem. Existe uma divergência considerável entre (i) ter o direito de governar sobre alguém, porque é vantajoso e (ii) ter o direito de controlar alguém para agir de uma certa maneira simplesmente quando o ato é vantajoso.

48 Ver De voto , 1.14.1, 1. 14.4, 1.14.8-10, II. 7.1, II.7.9, II.7.12, II.8.12, X. 5.5-7.

49 Defender um hipotético estado político pré-lapsariano: "o dominium político priva o homem nem de sua liberdade considerada em simpliciter, nem de sua autonomia sobre suas ações. Nem sujeita-o a outra pessoa assim como para servi-la para as vantagens desta pessoa. Mas [o dominium político] sujeita-o para obedecer o líder naqueles atos honestos que resultam em seu bem privado ou coletivo e vantagem.” O.S.D. V.7.12.

50 Thomas Hobbes, Leviathan, II, ch. 17, §13.

51 O.S.D. V.7.13 
Em primeiro lugar, a vantagem é a justificativa para a transferência de dominium sobre uma parte da nossa liberdade para um governante. Os comandos do cidadão são legítimos por causa do dominium do governante, independentemente da questão de saber se cada um desses atos contribui de forma independente para a vantagem. Para Suárez, cada um dos comandos do governante (dado sob a lei) deve passar no teste de ser ou não vantajoso. Da mesma forma, um médico pode ter o direito à minha obediência às suas prescrições que me curarão, mas ele não tem o direito irrestrito à minha obediência, alegando que se ele tivesse esse direito ele melhoraria minha saúde.

\section{O que a cidade causa por "decorrência natural”?}

Intérpretes como Merêa, Gómez Robledo, Durau Alves, Gierke e Schröck defendem a opinião de que, para Suárez, o direito político e a obrigação não se seguem do consentimento ao embasarem-se na tese suareziana de que o poder flui da cidade, e não das vontades que ajudaram a formá-la. ${ }^{52}$ A cidade causa o poder político através daquilo que Suárez chama de "decorrência natural". Outros intérpretes, como Vidal Abril Castello, Pedro Calafate e Luis Recaséns Siches, consideram autoexplicativo de que uma coisa produza por si mesma um direito através deste modo causal. ${ }^{53}$ Esta consideração [destes intérpretes] mostra uma notável falta de curiosidade sobre a intrigante idéia de algo que tem a capacidade de criar um direito por si mesmo.

O propósito desta seção é atacar a "interpretação tradicional” em seu âmago. O efeito produzido por decorrência natural não é, como defendido pela maioria dos intérpretes, o direito dos governantes sobre os cidadãos, mas, sim, é o direito original da cidade em ser autônoma.

52Ver n. 7 .

53 Esta falta de inquisitividade é a norma na maioria das obras interpretativas, por exemplo: Abril Castello, 'La obligación política según Suárez, Miscelánea Comillas 67 (1977), 229-296 (especialmente 257, 270-1) (a versão francesa mais cuerta L'Obligation politique chez Suárez. Bilan et perspectives', Archives de Philosophie 42 [1979], 179-203); Pedro Calafate, 'A ideia de soberania em Francisco Suárez' in Francisco Suárez (1548-1617): Tradiçao e modernidade (Lisbon, 1999), 256; Luis Recaséns Siches, La filosofia del derecho de Francisco Suárez (Madrid, 1927), 134. Ao meu conhecimento, a única tentativa de ligar a noção de "decorrência natural” na metafísica e na política é Eleuterio Elorduy, 'La acción de resultancia en Suárez', Anales de la Cátedra Francisco Suárez 3 (1963), 45-71. O valor deste artigo reside grandemente nas coleções de alguns textos relevantes. 
Portanto, para Suárez, a obrigação política e o direito correlato não são o que flui da cidade por decorrência natural, mas sim, como argumentado acima, são uma conseqüência do consentimento dos indivíduos.

Suárez argumenta, no De legibus III.3.5 que "Deus confere o poder no modo de uma propriedade que resulta da natureza, do mesmo modo que ele dá a forma, dá também o que é consequiência da forma." ${ }^{54}$ Deus gera a cidade, e o poder político "emana” dela.

Como outros termos que Suárez usa em suas obras políticas, "decorrência natural” é um termo emprestado de sua metafísica. A decorrência natural é um modo peculiar de causalidade pelo qual a substância produz seu próprio acidente ou propriedade. Uma substância pode agir não só como causa material e formal, mas também como uma causa eficiente de algumas de suas propriedades. ${ }^{55} \mathrm{~A}$ propriedade causada por decorrência natural não pode existir separada de sua substância, e deve ser algo que em alguma medida aperfeiçoa-a. ${ }^{56}$ Portanto a decorrência natural consuma o ato da geração porque a substância produz por si mesma estas propriedades que a completam. ${ }^{57} \mathrm{O}$ típico exemplo de Suárez de decorrência natural é a alma que produz seus próprios poderes uma vez que foi criada. ${ }^{5}$

O axioma metafísico que "quem dá a forma, também dá o que é conseqüência da forma” significa que o gerador da substância é a causa primeira das propriedades causadas por decorrência natural. ${ }^{59} \mathrm{~A}$

54D.L. 3.3.5: "hanc potestatem dari a Deo per modum proprietatis consequentis naturam, eo modo quo dando formam dat consequentia ad formam" DL. 3.3.6: "Portanto é corretamente entendido que [esta potestas] existe como uma propriedade resultante de tal corpo místico, já constituído com o modo de ser [que ele tem] e não contrariamente.” D.F. III.2.6: "o fato de que uma vez que os indivíduos se congregam politicamente em uma cidade, o poder político resulta sem a intervenção de alguma vontade criada mostra que este poder procede imediatamente de Deus e da ordem da razão (que o demonstrao e que somente intervem uma decorrência natural ou conseqüência da natureza.”

55 D.M. XIIX.3.4,5,6,

56 D.M. XIIX.3. 11,14.

57 Para Suárez sobre a causalidade da substância por seus próprios acidentes, e sua discrepância com João de São Tomás, ver Dennis Des Chene, Physiologia: Natural Philosophy in Late Aristotelian and Cartesian Thought (Ithaca, NY, 1996), 159-61.

58 De Anima d. 3 q. 3. § 8, 14 da edição crítica de Salvador Castellote, Commentaria una cum quaestionibus in libros Aristotelis 'De Anima' (Madrid, 1981) vol. 2. D.M. XIIX.3.8,13. Sobre Suárez, quanto a causalidade das almas por seu próprios poderes, ver Des Chene, Life's Form: Late Aristotelian Conceptions of the Soul (Ithaca, NY/London, 2000), 148-9.

59 “Qui dat formam dat consequentia ad formam”, D.M. XIIX.3.14, de Anima d. 3 q. 3, § 5, 14. Também em D.L. III.3.1, D.F. III. 1.7. Suárez atribui o princípio a Aristóteles. Anteriormente Jean Buridan 
substância é a causa contígua destas propriedades. Como Suárez diz, a substância, de algum modo, é um "instrumento" do gerador que causa as propriedades. $^{60}$ Mais propriamente, a causa contígua é a forma da substância que, como um princípio de operação, cria a propriedade. ${ }^{61}$ Portanto as propriedades acarretadas por decorrência natural são ditas a ser "conseqüência da forma”.

Uma propriedade que resulta por decorrência natural aparece simultaneamente com a substância da qual ela é inerente, como a luz aparece simultaneamente com a criação do sol. ${ }^{62}$ Ainda, de acordo com Suárez, a substância deveria ser capaz de existir sem ter esta propriedade. Isto é, ela deve ser possível em princípio para impedir o efeito (a propriedade) sem destruir a substância. ${ }^{63}$ Ainda que a água produza refrescancia por decorrência natural, a refrescancia pode ser impedida por uma ação externa (aquecimento, por exemplo).

Como a causalidade por decorrência natural se aplica à política? Suárez usa a decorrência natural primeiramente para prevenir uma implicação indesejada da visão de que o poder político vem de Deus: que Deus expressamente doou (por um ato sobrenatural) o poder político para a cidade. Para impedir esta implicação Suárez argumenta que o poder político emana da cidade por decorrência natural. Isto é, a cidade é a substância que produz de si mesma e para si mesma a propriedade do poder político. Isso permite a Suárez sustentar que Deus permanece a

atribuiu a um dos comentários de Averrois, Comentários sobre a Física VII, provavelmente se referindo a "generans dat corpori simplici formam suam et omnia accidentia contingentia formae" em Long Commentary, VIII, 32 in Aristotelis opera cum Averrois commentariis (Venice: Apud Junctas, 15621574) [edição facsimile (Frankfurt, 1962)] vol. 4, p. 370. A passagem usada no sentido de Suárez ocorre também em Francisco Vitoria, Relectio de postestate civilis $§ 6$. O gerador é alguém ou algo que altera a forma de uma coisa de modo que se ela se torna uma nova coisa, como um artesão transforma uma bloco de madeira em uma cadeira.

6o D.M. XIIX.3.10

61 As "propriedades acidentais, especialmente aquelas que seguem ou são devidas a [consequuntur aut debentur] razão da forma, são causadas pela substância de um modo não somente material e final, mas também efetivo por decorrência natural [...] Deste modo é mais fácil compreender que a conexão natural entre a forma e as propriedade, e a ordem per se entre as duas.” Por exemplo, o princípio responsável pelo auto-resfriamente natural da água é a forma substancial da água. DM. XIIX.3.7 Also in D.M. XIIX.3.10, D.M. XIIX. 3.13.

62 D.M. XIIX.3.8. Exemplo do sol em Anima d. 3 q. 3. § 7.

63 D.M. XIIX.3.13. 
primeira causa do poder político. ${ }^{64}$ A cidade consuma o trabalho de Deus por produzir através de decorrência natural propriedades que são necessárias para sua subsistência.

A interpretação tradicional de Suárez sustenta que a decorrência natural bloqueia qualquer conexão causal direta entre as vontades humanas e a obrigação política. A influência das vontades humanas se estende somente para a geração da cidade. É a cidade que de algum modo causa o domínio político sobre os cidadãos. Em uma analogia que Suárez mesmo propõe, enquanto os pais são a causa contígua da criança, a criança tem domínio sobre seus membros não por uma vontade especial dos pais, mas sim por decorrência natural, na medida em que ela tem o uso da razão. ${ }^{65}$ Nesta interpretação o poder político produzido por decorrência natural abrange primeiramente o direito da cidade sobre os cidadãos, e suas obrigações correlatas.

Eu sugiro, porém, que dado sua metafísica, Suárez não poderia ter sustentado que a obrigação política e o direito correlato fossem causados pela cidade como causa contígua. Portanto o "poder político" que emana da cidade significa outra coisa para ele. Nós precisamos de uma compreensão mais refinada do efeito que a cidade causa por decorrência natural.

Para Suárez, a cidade é gerada por um ato da vontade humana em conjunto com um ato da vontade de Deus. Suárez expressa isso dizendo que as vontades humanas suprem a questão para a cidade, ${ }^{66}$ mas é Deus quem dá a forma. A "questão" da cidade é o consentimento dos indivíduos

64 Por razões de tamanho e duração, eu excluo da presente análise a visão de Suárez sobre se os poderes causais eficientes podem ser atribuídos tanto a Deus e às criaturas e de que modo. Estas visões subjazem a posição de Suárez sobre o assunto (aqui a criatura é a cidade e a potestas a coisa criada). Sobre isso ver: Alfred Freddoso, 'Suárez on Metaphysical Inquiry, Efficient Causality, and Divine Action, in Francisco Suárez, On Creation , Conservation , and Concurrence: Metaphysical Disputations 20-22 (South Bend, IN, 2002), lxxxvi-cv, and his 'Gods General Concurrence with Secondary Causes: Why Conservation is not Enough', Philosophical Perspectives , 5 (1991), 553-58

65 "Assim como [...] a vontade dos pais com respeita a geração só é necessária, mas nenhum ato da vontade outorga a criança com liberdade, ou com a outra faculdades natauris que não são essencialmente dependentes de um ato especial da vontade sobre a parte dos pais, sendo ao contrário uma conseqüência natural; mesmo assim, com respeito a questão sob discussão, a vontade humana é necessária para que os homens possam unir em uma só comunidade perfeita, mas nenhum ato especial da volição sobre suas partes é requerido para o fim que esta comunidade possuirá a dita potestas, que surge da verdadeira natureza das coisas, e da providência do Autor da natureza, assim neste sentido é corretamente dito ter sido conferido imediatamente por Ele." D.L. III. 3. 6.

66 D.L. III. 3.2. 
em criá-la. Mas só o consentimento dos indivíduos é insuficiente para conseguir isso. Como Deus informa a estas volições humanas? Na filosofia jurídica de Suárez, a volição humana não pode ser moralmente efetiva (ela não poder criar direitos e obrigações) sem o influxo divino. O vínculo de uma obrigação moral é derivado da lei natural. ${ }^{67} \mathrm{~A}$ lei natural prescreve o que Deus julga como bom, e é bom. Ainda, a fonte do vínculo não é a bondade do ato como tal, mas a prescrição divina dele. ${ }^{68}$ Portanto Deus provê a forma da cidade outorgando eficácia moral para o consentimento dos indivíduos, de modo que o consentimento é capaz de causar os respectivos direitos e obrigações necessários para a união moral da cidade.

Por conseguinte, Suárez escreve que a potestas é uma propriedade que se apresenta "como uma conseqüência da natureza, ou seja, por uma ordem da razão natural ${ }^{69}$ e uma vez que este corpo foi constituído o poder em questão existe nela imediatamente e por força da razão natural." ${ }^{\circ 0}$ Aqui "razão natural” é o meio pelo qual nós discernimos e nos controlamos para agir de acordo com os preceitos da lei natural. ${ }^{11}$ Assim, dizer que o poder político é um efeito da "forma da cidade" significa que o poder político é um efeito dos vínculos morais compartilhados pelos cidadãos. Estes vínculos, por sua vez, resultam do fato de que Deus deseja

67 Para uma apresentação sucinta da teoria da lei natural de Suárez, ver Finnis, Natural Law and Natural Rights (Oxford, 1982), 42-48. Uma abordagem detalhada em William E. May, 'The Natural Law Doctrine of Francis Suárez', New Scholasticism 58 (1984), 409- 425, esp. 418.

68 Essa é uma asserção sobre a fonte do vínculo das prescrições da lei natural, e deixa em aberto a possibilidade que, para Suárez, haja um "laço natural" sobre seu próprio direito, independentemente da vontade de Deus. Aqui eu não estou pressupondo um voluntarismo forte da parte de Suárez. Para uma crítica persuasiva recente de uma interpretação voluntarista de Suárez, ver Terence H.Irwin, Obligation, rightness, and natural law: Suarez and some critics (unpublished paper draft). Sobre isso também ver J.B. Schneewind, The Invention of Autonomy (Cambridge, 1997), 60-1, Knud Haakonssen, Natural law and moral philosophy (Cambridge, 1996), 19-23, e ainda Stephen Darwall, The British moralists and the 'internal ought': 1640-1740 (Cambridge, 1995), 25-6.

69 D.L. III.3.5.

70 D.L. III.3.6.

71 "Os efeitos legais no caso da lei natural procedem imediatamente de uma ordem da razão, pois esta ordem direciona e vincula e é uma regra da consciência que censura ou aprova o que é ffeito, assim esta lei do tipo em questão [i.e.natural] consiste na referida ordem.” D.L. II.5.12. A ordem da razão natural, de acordo com Suárez, gera em nós obrigações porque é a vontade de Deus que nós agimos de acordo com elas. D.L. II.6.8. Ver Jaime Fernández-Castañeda, 'Right Reason in Francis Suárez, The Modern Schoolman 45 (1968), 105-122 (esp. 1 15-122). Visto que a potestas é um resultado da lei natural, é somente análogo a propriedade natural: é "uma propriedade natural assim falar" [ut sic dicam] e uma "propriedade quase-natural." D.L. III.3.7. 
o consentimento dos indivíduos para vinculá-los em uma estrutura comum de direitos e obrigações. Assim, de acordo com Suárez, ao consentir criar uma cidade os indivíduos criam tanto a cidade (vínculos morais compartilhados) e, involuntariamente, o direito da cidade em governar sobre eles.

Esta conclusão pode parecer inconsistente com a crença de Suárez de que o poder político é causado pela cidade por decorrência natural, ao invés de pelo consentimento dos indivíduos em criar uma cidade. A cidade e o consentimento parecem duas causas competidoras que atribuem a si mesmas um e o mesmo efeito. Porém é mais plausível interpretar Suárez como alguém para quem cada uma destas causas é responsável por um diferente efeito.

Poderia a sujeição política ser a potestas causada pela cidade por decorrência natural? Não é o caso. A cidade não pode existir sem ter o direito político sobre os cidadãos, já que este direito é essencial para seu ser uma comunidade política. Não é o caso que a cidade causa por decorrência natural algo que ela deve já possuir e sem qual ela não pode existir.

É uma alternativa a ser considerava se o poder político produzido por decorrência natural é diverso da sujeição política. Nós podemos distinguir entre dois conjuntos de direitos e obrigações e dizer que o primeiro conjunto, que dá forma à cidade (ou seja, uma teia horizontal de vínculos entre os cidadãos) produz um segundo conjunto (ou seja, uma relação vertical de cada cidadão com o governante). Mas essa opção é excluída de antemão pelo próprio Suárez, que caracteriza os vínculos morais constitutivos que dão forma à cidade primeiramente como vínculos de sujeição sobre a parte dos cidadãos ao governante ou à cidade. ${ }^{72}$

Nós precisamos de um modo diferente de conceber o poder político que emana da cidade por decorrência natural. Deveríamos começar notando que nos textos nos quais a decorrência natural tem um papel central, Suárez não tenta explicar as obrigações dos cidadãos para com a cidade. Ao contrário, a questão que o preocupa é essa: quando os cidadãos constituem a cidade como um todo unificado e quem tem a liderança sobre este todo? Aqui a potestas política é concebida por Suárez não tanto como os direitos da cidade sobre os cidadãos mas sim como o 
direito da cidade contra outros governantes potenciais, tais como poderes estrangeiros.

$\mathrm{Na}$ analogia de Suárez da criança, os pais geram um ser vivo dotado de razão. A questão é sobre quem tem a liderança (dominium) dessa pessoa. Suárez diz que o novo ser humano é seu próprio mestre e obtém este direito por decorrência natural. O direito à autonomia não é um direito contra as partes constituintes do corpo, mas contra os aspirantes potenciais ao governo sobre esta pessoa.

Considere agora o caso da cidade. Os cidadãos, ao reunirem-se por consentimento, criam um ser. Eles o constituem ao gerar obrigações entre os cidadãos e o governante (quem quer que tenha este posto). Conseguintemente, a cidade tem direitos não somente contra cada parte do todo (i.e., os cidadãos), mas também contra os aspirantes ao governo sobre o corpo político, tais como poderes estrangeiros.

Quanto a questão sobre quem tem direito ao governo da cidade, Suárez responde que é o próprio direito alienável original da cidade. Isso permite dizer que o poder político causado por decorrência natural não é uma propriedade essencial da cidade. Como a cidade pode alienar seu poder ela é governo por livre alienação, justamente alienada sem deixar de ser uma cidade (assim como a criança na analogia).

O ponto crucial aqui é que Suárez não faz do direito e obrigação política (i.e. sujeição política) um efeito de decorrência natural. Portanto, é incorreto sustentar - como a interpretação tradicional faz - que porque Suárez crê que o poder político segue por decorrência natural então a obrigação política não segue do consentimento individual. De acordo com Suárez, é a autonomia da cidade sobre si mesma que não se segue do consentimento individual, e não a obrigação política.

Nós podemos perguntar: como a decorrência natural é útil para explicar a autonomia da cidade? A resposta de Suárez a esta questão não é inteiramente satisfatória. Vejamos sua argumentação. De onde o direito vem? Ele procede por eliminação. O direito não pode vir de uma vontade humana individual porque, em um estado pré-político, os indivíduos não tem nenhum poder político que eles possam transferir para a cidade. Uma alternativa é Deus, mas não há regristro de doação de propriedade sobre a cidade. Suárez infere que é a cidade, por decorrência natural, que causa o direito à autonomia. 
Suárez não nos conta qual é a ação que a cidade faz para produzir sua própria autonomia, e nenhuma [ação] pode ser observada. Em resposta, deveria ser notado que, para Suárez, uma ação que produz algo não possui existência real como uma coisa separada. Ao invés, a ação "existe no produto": ela difere do produto somente em um sentido modal. ${ }^{73}$ "Ação" simplesmente designa o produto concebido como algo que tem tal e tal origem. Imagine uma cadeira feita de tábuas de madeira que vem de uma floresta. Suponha que a cadeira é miraculosamente substituída por Deus por uma replica idêntica. As duas cadeiras são diferentes porque sua origem é diferente. ${ }^{74}$ Semelhantemente, para Suárez, a propriedade da cidade sobre si mesma é diferente de qualquer outra possível propriedade (ou produtos, tal como a propriedade concedida pela cidade por doação divina), em que ela procede da cidade mesma.

Não há ação "fora” do produto. A ação é simplesmente um modo de existência do produto. Aqui nós não precisamos olhar para alguma ação observável feita pela cidade que explicaria como o poder político surge. Considere a analogia do fogo. O fogo inevitavelmente queima, no mesmo instante em que ele surge. Mas o calor não é o fogo. Agora nós podemos perguntar: qual ação o fogo faz para produzir calor? A ação é simplesmente sua existência.

Dizer que a liderança ou propriedade da cidade é causada por decorrência natural é principalmente um modo de dizer que nenhuma causa externa pode ser achada para sua liderança. A decorrência natural

73 Suárez discute estas questões em sua análise da diferença entre criatura e criador. Em muitos respeitos, a questão é a mesma como esta sobre a diferença entre a ação e o efeito. Para Suárez a criatura não é absolutamente diferente em realidade do terminus da ação da criação, mas somente um diferente modex natura rei do mesmo terminus [modus quidam ex natura rei distinctus ab ipso termino] D.M. XX.4. 15 e D.M. XX.4. 17. O mesmo pode ser dito da ação não-criativa: "no esquentar do fogo, e em casos similares, a dependência pelo qual o esquentar no paciente é produzido é a ação do calor que teve, existe no fogo, porque por nenhuma outra razão que esta é um certo fluir que emana dele.” D.M. XX.4.21. Ver Freddoso, Ow Creation, Conservation, and Concurrence, lxxii-lxxiii. Note que em D.M. XIIX.3.13 Suárez já sugere isso: "isto que a decorrência natural acresce a entidade da forma acidental inerente [o produto] não é nada mais senão um modo particular de dependência intrínseca da propriedade com respeito a sua forma considerada como um princípio ativo, mas a dependência [da propriedade] sobre o princípio agente e a ação são a mesma coisa."

74 Para uma abordagem moderna deste tipo de modalidade, ver Saul Kripke, Naming and Necessity (Oxford, 1980), 112-116 
não revela um mecanismo inteligível pelo qual a cidade se torna sua própria líder.

O emprego de Suárez da metafísica da causalidade tem um aspecto analógico. ${ }^{75} \mathrm{O}$ empréstimo de noções metafísicas é intencional para permitir leitores metafisicamente familiarizados a compreender melhor certos aspectos de sua teoria moral e política. Isso não quer dizer que essas noções emprestadas podem ser usadas com o mesmo rigor no seu novo contexto moral e político (que Suárez parece estar consciente). Para dar um exemplo: suponha um cientista político explique um processo político por emprestar da física a noção de "reação em cadeia". Para entender essa asserção nós precisamos examinar o conceito de reação em cadeia em seu contexto original e então identificar as similaridades que o cientista político teve em mente quando usou essa noção física para descrever o processo político. Eu argumentei que Suárez empresta a noção de decorrência natural para nos fazer ver como a autonomia original da cidade não requer qualquer ato além de sua própria constituição.

Para resumir essa seção: o que Suárez afirma ser um resultado de decorrência natural não é a obrigação política dos cidadãos e o direito político da cidade sobre eles, mas sim é o direito da cidade para inicialmente possuir a si mesma. Aqui, a despeito das alegações contrárias, a obrigação política permanece, para Suárez, como um resultado direto do consentimento.

\section{Resumo}

Neste artigo eu tento desarmar objeções reais e possíveis, contra a alegação de que, para Suárez, é o consentimento que cria a obrigação política.

(i) Primeiro eu discuto a aparente irrelevância do consentimento no capítulo do De legibus no qual Suárez anuncia sua intenção de demonstrar a legitimidade moral da potestas. Tal problema é uma conseqüência de expectativas postas no lugar errado. A intenção de Suárez neste capítulo é mostrar que nós somos naturalmente inclinados a sujeição

75 Isso se torna claro quando Suárez diz que a potestas, como um resultado da lei natural, é somente parecida à propriedade natural: "uma propriedade natural, por assim dizer" e uma "propriedade quase-natural.” D.L. III. 3.7. 
40o | Veritas | Porto Alegre, v. 63, n. 1, jan-mar. 2018, p. 376-401

política, e não esboçar os modos nos quais tal sujeição pode ser legitimadamente introduzida.

(ii) Para Suárez é o consentimento que constitui a cidade ao criar obrigações morais vinculantes que congregam os cidadãos em uma "união moral.” A descrição de Suárez dos efeitos morais do consentimento é impressionantemente similar a sua descrição dos efeitos morais das promessas. Estes efeitos - a saber, obrigações e direitos - não podem ser impedidos por qualquer atitude volitiva subseqüente uma vez que eles foram criados pela execução de um ato performativo. Suárez faz um argumento semelhante quando diz que a sujeição não pode ser impedida uma vez que os cidadãos constituíram a cidade. Nossa incapacidade de impedir a sujeição política uma vez que nós consentimo-la ao constituir a cidade, não deveria ser usada como base para quebrar uma possível ligação causal entre o consentimento e a obrigação política.

(iii) A relutância de Suárez em falar dessa potestas como um resultado de uma transferência ou alienação dos direitos de autonomia é consistente com sua visão de que os votos e promessas não precisam aparecer conjuntamente, ou que pressupõem alienação dos direitos. A obrigação e o direito político são produzidos por um ato humano semelhante em suas consequiências morais a uma promessa. A teoria de Suárez difere de outros contratualismos em que o direito do governante sobre seus cidadãos não resulta de uma transferência de seus direitos. Portanto o governante não é, como em Hobbes, o proprietário de parte dos direitos dos cidadãos sobre si mesmos.

(iv) A confiança de Suárez sobre a noção metafísica de causalidade por decorrência natural para explicar como a potestas política flui da cidade é mostrada não para contradizer a visão de que é o consentimento que causa a obrigação e o direito político. Não são os direitos do governante sobre os cidadãos e a obrigação política correlata que a cidade causa por decorrência natural, mas, sim, o direito original da cidade à autonomia que é criada simultaneamente com a formação da cidade, e isso é feito através do consentimento. As quatro objeções contra a afirmação de que para Suárez o consentimento causa obrigações políticas e direitos políticos correlatos, falham. Suárez propõe, de fato, uma explicação da origem da obrigação política cuja base é o consentimento. Sem dúvida sua explicação é freqüentemente articulada na linguagem metafísica, que tende a ser mal compreendida. Visto que a teoria do contrato social é uma 
D. Schwartz - Francisco Suárez acerca do consentimento e da obrigação política | 401

teoria que faz a obrigação política diretamente dependente do consentimento, segue-se deste artigo que é correto considerar Francisco Suárez como um contratualista. ${ }^{76}$

\title{
Endereço postal
}

\author{
Universidade Federal do Paraná - Faculdade de Filosofia, Ciências e Letras \\ R. Gen. Carneiro, 46o - Centro, Curitiba - PR, Brasil
}

Data de recebimento: $24 / 12 / 2018$

Data de aceite: $11 / 03 / 2018$ 